\title{
Absorption behavior of riociguat: bioavailability, food effects, and dose-proportionality
}

Corina Becker ${ }^{1 * \dagger}$, Reiner Frey ${ }^{1}$, Christiane Hesse ${ }^{1}$, Sigrun Unger $^{2}$, Michael Reber ${ }^{1}$, Wolfgang Mueck ${ }^{1}$

From 6th International Conference on cGMP: Generators, Effectors and Therapeutic Implications

Erfurt, Germany. 28-30 June 2013

\section{Background}

Riociguat, an oral soluble guanylate cyclase (sGC) stimulator, is currently being investigated for the treatment of pulmonary hypertension. Riociguat has a novel dual mode of action, directly stimulating sGC, independent of nitric oxide (NO), and increasing sensitivity of
sGC to NO. Riociguat thereby restores the NO-sGCcGMP pathway, which is impaired in pulmonary hypertension. Three pharmacokinetic studies were performed to characterize the absorption behavior of riociguat including absolute bioavailability, food effects, and dose-proportionality.

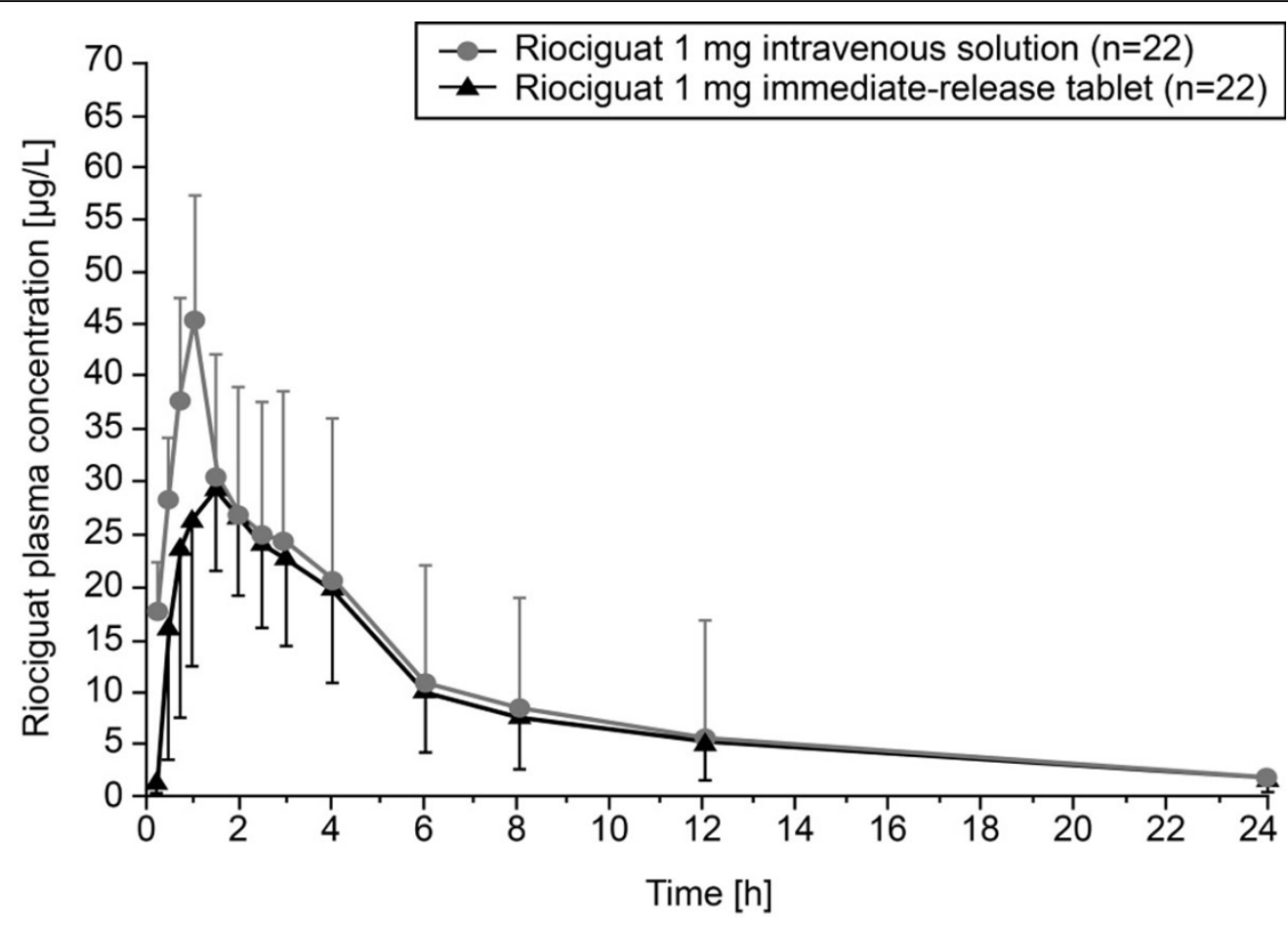

Figure 1 Plasma riociguat concentrations following single $1 \mathrm{mg}$ intravenous ( $\mathrm{n}=22$ ) or oral doses of riociguat ( $\mathrm{n}=22$ ) (absolute bioavailability study).

* Correspondence: corina.becker@bayer.com

+ Contributed equally

${ }^{1}$ Clinical Pharmacology, Bayer HealthCare Pharmaceuticals, Wuppertal,

Germany

Full list of author information is available at the end of the article

(c) 2013 Becker et al; licensee BioMed Central Ltd. This is an Open Access article distributed under the terms of the Creative Commons 


\section{Methods}

The pharmacokinetic and safety profiles of riociguat were investigated in three open-label, randomized, crossover studies in healthy male subjects. In the absolute bioavailability study, fasted subjects $(\mathrm{n}=22)$ received a single oral immediate-release dose of riociguat $1 \mathrm{mg}$ or intravenous riociguat $1 \mathrm{mg}$. In the food-effects study, subjects ( $\mathrm{n}$ $=23$ ) received a single oral dose of immediate-release riociguat $2.5 \mathrm{mg}$ after a 10 -hour fast or after a high-fat high-calorie breakfast eaten within 30 minutes of dosing. In the dose-proportionality study, fasted subjects $(n=24)$ received a single oral dose of riociguat $0.5,1,1.5,2$, or $2.5 \mathrm{mg}$.

\section{Results}

In the absolute bioavailability study, riociguat exposure was similar after oral and intravenous dosing and oral bioavailability was $94 \%$ (95\% confidence interval: $83-107$ )
(Figure 1). Mean $\mathrm{C}_{\max }$ of riociguat was slightly lower after oral dosing compared with intravenous dosing. In the food-effects study, a high-fat breakfast had little effect on the extent of riociguat absorption, although absorption was delayed (Table 1). In fed subjects, the $C_{\max }$ of riociguat decreased by $35.3 \%$ and $\mathrm{t}_{\max }$ increased compared with fasted subjects. In the dose-proportionality study, systemic exposure of riociguat was dose-proportional over $0.5-2.5 \mathrm{mg}$ (Figure 2) with low intra-individual variability and moderate-to-high inter-individual variability. Riociguat was well tolerated in all studies. The most common treatment-emergent and riociguat-related adverse events were headache, flushing, and nasal congestion across all studies.

\section{Conclusion}

Riociguat shows complete oral absorption with no clinically relevant food effects; riociguat can therefore be

Table 1 Riociguat pharmacokinetics following a single oral dose of riociguat $2.5 \mathbf{m g}$ in fed and fasted subjects (food-effects study)

\begin{tabular}{|c|c|c|c|c|c|}
\hline Parameter $^{a}$ & Fasted $(n=23)$ & Fed $(n=23)$ & Estimated fed:fasted ratio (\%) & $90 \% \mathrm{Cl}$ & $\% \mathrm{CV}$ \\
\hline$\overline{C_{\max }(\mu g / L)}$ & $84.2(44.7-152.7)$ & $54.8(28.9-91.4)$ & 64.7 & $57.8-72.5$ & 22.5 \\
\hline$t_{\max }(h)$ & $1(0.5-4.0)$ & $4(1.5-6.0)$ & - & - & - \\
\hline
\end{tabular}

$\mathrm{AUC}$, area under the plasma concentration-time curve; $\mathrm{Cl}$, confidence interval; $\mathrm{C}_{\max }$ maximum riociguat plasma concentration; $\mathrm{CV}$, coefficient of variation; $\mathrm{t}_{\text {max }}$ time to reach $C_{\max }$.

${ }^{a}$ Data are mean (range) except $t_{\max }$, which is median (range).

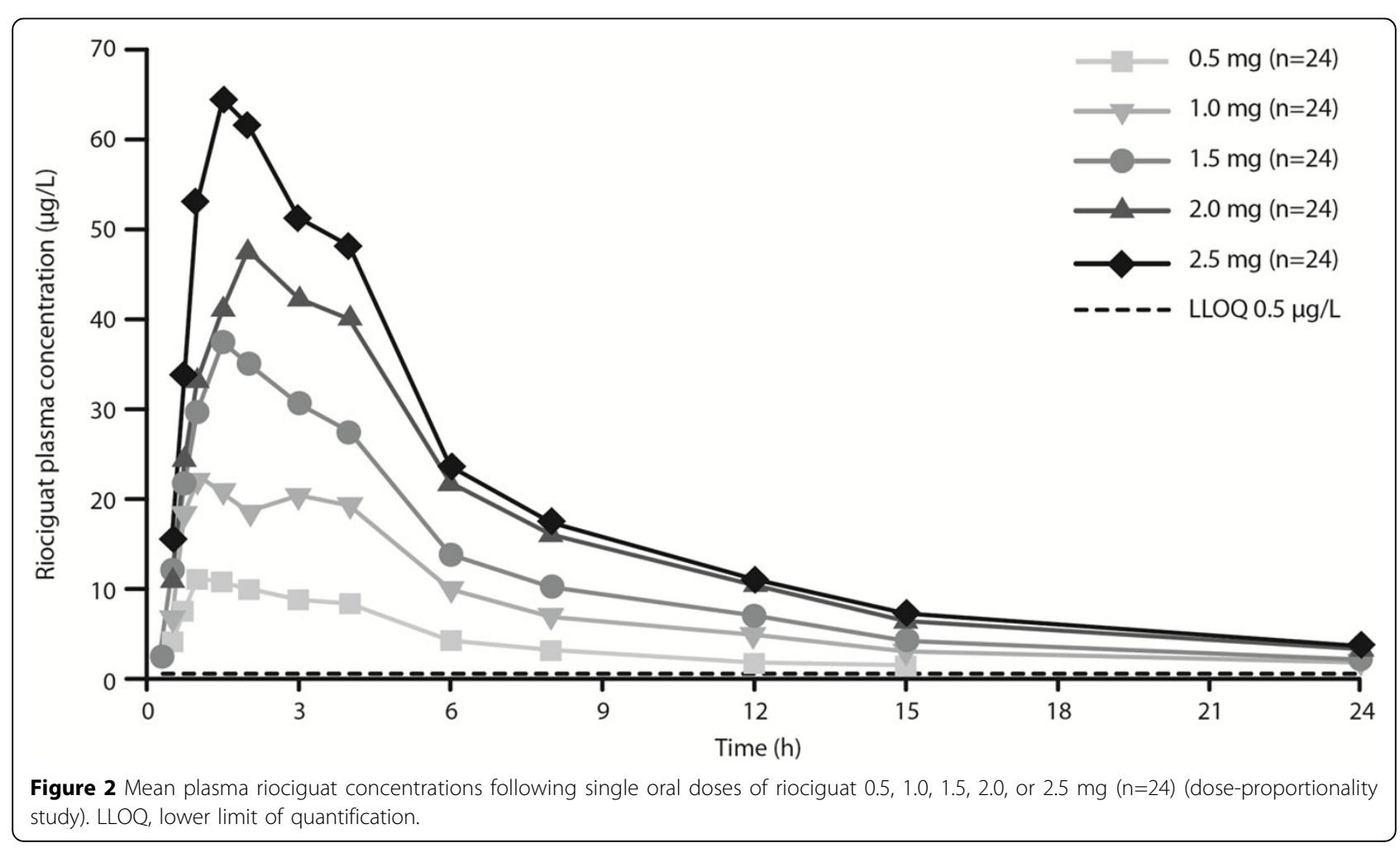


taken with or without food. Riociguat systemic exposure increased dose proportionally over all doses $(0.5-2.5 \mathrm{mg})$, supporting the suitability of the individualized dosetitration scheme used in the Phase III pulmonary arterial hypertension (PATENT) and chronic thromboembolic pulmonary hypertension (CHEST) studies.

\section{Acknowledgements}

The studies were funded by Bayer HealthCare Pharmaceuticals, Wuppertal, Germany. Medical writing assistance was provided by Adelphi

Communications Ltd, Bollington, UK and funded by Bayer HealthCare Pharmaceuticals.

\section{Authors' details}

'Clinical Pharmacology, Bayer HealthCare Pharmaceuticals, Wuppertal, Germany. ${ }^{2}$ Global Biostatistics, Bayer HealthCare Pharmaceuticals, Wuppertal, Germany.

Published: 29 August 2013

doi:10.1186/2050-6511-14-S1-P7

Cite this article as: Becker et al:: Absorption behavior of riociguat: bioavailability, food effects, and dose-proportionality. BMC Pharmacology and Toxicology 2013 14(Suppl 1):P7.

Submit your next manuscript to BioMed Central and take full advantage of:

- Convenient online submission

- Thorough peer review

- No space constraints or color figure charges

- Immediate publication on acceptance

- Inclusion in PubMed, CAS, Scopus and Google Scholar

- Research which is freely available for redistribution

Submit your manuscript at www.biomedcentral.com/submit 